\title{
Multi-walled carbon nanotube-reinforced magnesium alloy composites
}

Yasuo Shimizu, Shota Mikia, Toshiyuki Soga ${ }^{a}$, Isamu Itoh ${ }^{\mathrm{a}}$, Hiromitu Todoroki ${ }^{\mathrm{a}}$, Takashi Hosono $^{a}$, Kazuhiko Sakaki $i^{a}$ Takuya Hayashi ${ }^{a}$, Yoong Ahm Kim ${ }^{\mathrm{a}, *}$, Morinobu Endo ${ }^{\mathrm{a}}$, Singo Morimoto $^{\mathrm{b}}$ and Atsushi Koide,

${ }^{a}$ Faculty of Engineering, Shinshu University, 4-17-1 Waksato, Nagano-shi 380-853, Japan

${ }^{b}$ Nagano Techno Foundation, 1-18-1 Wakasato, Nagano-shi 380-0928, Japan

${ }^{c}$ Nissei Plastic Industry Co., Ltd., 2110 Sakaki, Nagano-Ken 389-0693, Japan

This study demonstrates the ability to fabricate lightweight, ductile but mechanically strong magnesium alloy (AZ91D) composites by introducing a small number of high crystalline multi-walled carbon nanotubes. It is demonstrated that $1 \%$ of relatively short and straight carbon nanotubes distributed homogeneously on the outer surface of magnesium powders act as an effective reinforcing filler to prevent deformation, thereby contributing to the enhanced tensile strength of magnesium alloy composites (e.g., from 315 to $388 \mathrm{MPa}$ ).

Keywords: Carbon nanotubes; Magnesium alloy; Powder processing; Mechanical property

There has been strong recent interest in developing lightweight and high-strength materials to improve the energy-efficiency through the weight reduction of automobiles and aircrafts. For these purposes, magnesium alloys have attracted a lot of attention [1-3], as they have low density in its purest form, and in addition, they have been proved to have good mechanical properties through the incorporation of structural filler (e.g., silicon carbide whisker, aluminum and graphite particles, and carbon fibers) [4-7]. Within this context, the dimensionally nano-sized, mechanically strong, electrically and thermally conductive carbon nanotubes [8-11], considered to be the ideal reinforcing filler in various composite systems [12-15], have been incorporated into magnesium matrix [16-19]. Recently, Goh et al. [19] reported a simple way of preparing nanotube-reinforced magnesium composite by powder-powder mixing and subsequent hot extrusion processes. However, low enhancement (only $5 \%$ ), or even a decrease in, tensile strengths in nanotube-reinforced magnesium composites (see Table 3 in ref. 19) could be explained by the presence of aggregated carbon nanotubes within a magnesium matrix. To exploit carbon nanotubes fully as a mechanical reinforcing filler in a magnesium matrix, optimized fabrication processes including homogeneous dispersion of carbon nanotubes must be 
developed to achieve high mechanical properties for their use in the major components of automotives.

This study reports an appropriate fabrication route for preparing high-density carbon nanotube-filled magnesium alloy composites through the suitable selections of filler and matrix alloy, followed by vacuum hot-press and extruding processes, and shows, that such composites reinforced by $1 \%$ of shortened linear carbon nanotubes have moderate ductility and largely enhanced high-tensile strength (e.g., from 315 to $388 \mathrm{MPa}$ ). The preparation process involved the mechanical shortening of long carbon nanotubes. Technical reasons for selecting short and straight carbon nanotubes are their high dispersibility in magnesium alloy matrix and their theoretically expected good reinforcing effect similar to that for the long tubes [20]. This work also makes a detailed study of the interfacial state between nanotubes and magnesium matrix.

In preparing carbon nanotube-reinforced magnesium alloy composite, we first, prepared AZ91D-type magnesium alloy (see Table 1) powders with diameter of $100 \mu \mathrm{m}$ or less using zirconia balls with diameter of $10 \mathrm{~mm}$ in a tri-axial vibrating-type ball miller (TKMAC-1200L) with a rolling rate of $800 \mathrm{rpm}$ for $6 \mathrm{hrs}$ in argon (Fig. 1a). The high-purity and high crystalline multi-walled carbon nanotubes, prepared by the catalytic chemical vapor deposition method and the subsequent high-temperature thermal treatment in argon [21, 22], were mechanically shortened to have a length distribution of $\sim 5 \mu \mathrm{m}$ (Fig. 2b) using a high speed blade cutting machine (Wonder Blender WB-1, Osaka Chemical Inc). Then, magnesium powders and shortened carbon nanotubes $(\sim 20 \mathrm{~g})$ were physically blended with zirconia balls (diameter 1 $\mathrm{mm}, 20 \mathrm{~g})$ in a container $(125 \mathrm{ml})$ using the same tri-axial ball miller with a rolling rate of 800 rpm for $5 \mathrm{hrs}$ in argon. The absence of the aggregated carbon nanotubes for the magnesium alloy powder containing $1 \%$ carbon nanotubes indicates that short carbon nanotubes are homogeneously impinged on the near surface of magnesium alloy particles (see Fig. 1c). In the case of the magnesium alloy powders containing $5 \%$ carbon nanotubes, the observed aggregated carbon nanotubes are indicative of non-homogeneously distributed carbon nanotubes (Fig. 1d). Next, the magnesium powders containing 0.5 - $5 \%$ carbon nanotubes were hot-pressed in a molder to form precursor at $823 \mathrm{~K}$ for $5 \mathrm{hrs}$ by applying a pressure of $25.5 \mathrm{MPa}$ in a vacuum $<10 \mathrm{~Pa}$. The carbon nanotube-reinforced magnesium alloy composites were finally obtained in a form of rod (Fig. 1e) (diameter $6 \mathrm{~mm}$, length $120 \mathrm{~mm}$ ) by extruding precursors at $723 \mathrm{~K}$ with an extrusion ratio of 9:1. There was no distinctive defect in appearance. For these extruded rods, solution treatment was carried out at $683 \mathrm{~K}$ for 15 minutes and artificial aging at 
$473 \mathrm{~K}$ for $15 \mathrm{hrs}$, respectively.

For these dumbbell-shaped specimens (gauge length $15 \mathrm{~mm}$, diameter $4 \mathrm{~mm}$ ), the mechanical properties were measured using an AG2501S (Shimazu) with a crosshead speed of $0.5 \mathrm{~mm} / \mathrm{min}$. Stress-strain curves for the pristine and nanotube-filled magnesium composites are shown in Fig. 2 and their tensile properties and densities are summarized in Table 2. Note that the tensile property of the milled, consolidated and extruded AZ91D rod sample was used as a reference. The elastic modulus, tensile strength, $0.2 \%$ proof stress for the carbon nanotube-filled composites increased with increase in the number of carbon nanotubes added, and they reached maximum values when $1-1.5 \%$ of carbon nanotubes were added. In particular, the tensile strength of magnesium alloy containing $1 \%$ carbon nanotubes was 388 $\mathrm{MPa}$, which is comparable to that of the generally used mild steel in automobiles. Tensile properties greatly improved by introducing a small amount of carbon nanotubes could be explained by the homogenous distribution of short carbon nanotubes in the vicinity of magnesium grain boundaries, because short carbon nanotubes with an average length of $5 \mu \mathrm{m}$ were believed to impinge on the near-surface of magnesium alloy powders very homogenously during a triaxial mixing process.

To confirm the above interpretation, the cross sectional texture of the rods was observed by electron probe micro-analysis (EPMA, Shimadzu). As shown in Fig. 3a-c, most of the carbon nanotubes were situated predominantly in the vicinity of magnesium grain boundaries. In addition, they were distributed in a singular fiber, which was confirmed by SEM (JEOL, JSM7000F) observation on the etched surface with $0.04 \%$ hydrochloric acid solutions for $40 \mathrm{~s}$ (Fig. 3d). As a result, the strengthened near-surface of magnesium domains by a suitable coverage of carbon nanotubes is highly resistant to deformation, and thus contributes to the enhancement of tensile properties when a suitable amount of carbon nanotubes are added. This interpretation is supported by the observation that the ductility was not extremely reduced (Table 2). Unfortunately, when the added amounts of carbon nanotubes are $>1.5 \%$, the deteriorations in tensile properties could be explained by the non-homogeneous distributed carbon nanotubes (the inset in Fig. 1d shows the aggregated carbon nanotubes) between magnesium powders and thereby the formation of pores and defects.

Up to now, there have been two reports on the mechanical properties of AZ91D-type magnesium composites. Nakagawa et al. reported the tensile strength of $270 \mathrm{MPa}$ and the fractured strain of $1 \%$ from AZ91D-type magnesium reinforced with 11 volume $\%$ of alumina short fibers [23]. Also, Schroder et al. reported $400 \mathrm{MPa}$ of tensile strength for AZ91-type 
magnesium alloy reinforced with $15 \%$ of $\mathrm{SiC}, \mathrm{TiC}$ and $\mathrm{TiN}$ [24]. As compared with those previous reports, the nanotube-filled magnesium alloy composites prepared under our optimized conditions are ductile enough, and, furthermore, they showed high tensile strength up to 388 MPa.

The interfacial state between magnesium alloy and carbon nanotubes was also considered, because the formation of carbide $\left(\mathrm{Al}_{2} \mathrm{MgC}_{2}\right)$ was reported when the temperature was $>773 \mathrm{~K}$ and the aluminum level in magnesium alloy compositions was $>0.6 \%$ and $<19 \%$ [25]. Therefore, TEM (JEOL, JEM-2100F) observations and EDS mappings were carried out for the samples, which were prepared by ion milling. As shown in the elemental mappings in Figure 4, magnesium alloys containing homogeneously distributed aluminum elements occupied around carbon elements. Also, it is confirmed that there was an absence of void (Fig. 4e) and new phases (Fig. 4f) between carbon nanotubes and magnesium alloys. From the viewpoint of the bonding nature for the samples, it is rational to say that magnesium alloys have high capability to move on the outer surface of carbon nanotubes, and they do not have chemical reactivity to form new products such as carbides. Furthermore, the grain sizes of the pristine and nanotube-added magnesium alloys were observed. As shown in Fig. 5, all samples have similar grain sizes ranging from 5 to $20 \mu \mathrm{m}$, irrespective of the addition of carbon nanotubes. In the case of the pristine magnesium alloy, it seems that solution treatment and ageing procedures are critical steps for dissolving and precipitating $\beta$ phases, respectively [26]. In contrast, mechanically strengthened grain boundaries with the introduction of carbon nanotubes are suggested here for the following reasons: (a) there was not a large difference in tensile strengths of CNT 1\%-added magnesium alloys, whether they experienced ageing or not, even though this AZ91D alloy showed age hardening properties, (b) all samples shows similar grain sizes, and (c) ductility was greatly reduced from 14 to $5 \%$ owing to the decreased dislocation mobility. Simply speaking, the enhanced tensile strength of nanotube-added magnesium alloy could be ascribed to the mechanically strengthened grains owing to the presence of carbon nanotubes along the near-surface of grain boundaries. Therefore, the most important technical issue in fabricating high-strength nanotube-reinforced magnesium composite is how to disperse nanotubes within a matrix or how to avoid the aggregated state of carbon nanotubes which decrease the relative density of nanocomposite and act as crack initiator, as a result contributing to the deterioration in tensile strength of nanotube-reinforced $\mathrm{Mg}$ composite.

In summary, this study has shown a suitable way of fabricating light but mechanically strong AZ91D-type magnesium alloy composites with a tensile strength of $388 \mathrm{MPa}$ and a ductility of $5 \%$, simply by introducing a small number (1\%) of short and linear high-crystalline carbon nanotubes. It has been demonstrated that the short and linear carbon nanotubes impinged on the outer surface of magnesium particle $(\sim 100 \mu \mathrm{m})$ homogeneously acted as an effective 
reinforcing filler to prevent deformation and therefore strengthen the material. The current study is of technical importance because the magnesium alloy composites have high tensile properties comparable to aluminum and steel, and they could be used as lightweight materials in various transportation industries to save energy.

This work was supported by the Cluster (the second stage) of Ministry of Education, Culture, Sports, Science and Technology in Japan. The authors thank Tomohiko Yamakami for his kind TEM observation. 
[1] K.U. Kainer, Magnesium Alloys and Their Applications, Willey-VCH, 2000.

[2] W.L.E. Wong, M. Gupta, J. Mater. Sci. 40 (2005) 2875.

[3] H.Z. Ye, X.Y. Liu, J. Mater. Sci. 39 (2004) 6153.

[4] M. Zheng, K. Wu, C. Yao, Mater. Sci. Eng. A 318 (2001) 50.

[5] F. Wu, J. Zhu, Y. Chen, G. Zhang, Mater. Sci. Eng. A 277 (2000) 143.

[6] J.C. Viala, P. Fortier, G. Claveyrolas, H. Vincent, J. Bouix, J. Mater. Sci. 26 (1991) 4977.

[7] Y. Kagawa, E. Nakata, J. Mater. Sci. 11 (1992) 176.

[8] A. Oberlin, M. Endo, T. Koyama, J. Crys. Grow. 32 (1976) 335.

[9] M. Treacy, T.W. Ebbesen, J.M. Gibson, Nature 381 (1996) 678.

[10] H. Dai, E.W. Wong, C.M. Lieber, Science 272 (1996) 523.

[11] T.W. Ebbesen, H.J. Lezec, H. Hiura, J.W. Bennett, H.F. Ghaemi, T. Thio, Nature 382 (1996) 54.

[12] P.M. Ajayan, L.S. Schadler, C. Giannaris, A. Rubio, Adv. Mater. 12 (2000) 750.

[13] R.H. Baughman, A.A. Zakhidov, W.A. De Heer, Science 297 (2002) 787.

[14] E.T. Thostenson, Z. Ren, T.W. Chou, Composites Science and Technology 61 (2001)1899.

[15] Y.A. Kim, T. Hayashi, M. Endo, Y. Gotoh, N. Wada, J. Seiyama, Scripta Materialia 54 (2006) 31.

[16] J. Yang, R. Schaller, Mater. Sci. Eng. A 370 (2004) 512.

[17] E. Carreno-Morelli, J. Yang, E. Couteau, K. Hernadi, J.W. Seo, C. Bonjour, L. Forro, R. Schaller, Phys. Stat. Sol. 201 (2004) R53.

[18] C.S. Goh, J. Wei, L.C. Lee, M. Gupta, Mater. Sci. Eng. A 423 (2006) 153.

[19] C.S. Goh, J. Wei, L.C. Lee, M. Gupta, Nanotechnology 17 (2006) 7.

[20] L.P. Biro, Carbon Filaments and Nanotubes: Common Origins, Differing Applications, Series E: Applied Sciences, Vol. 372, 2001.

[21] M. Endo, Chem. Tech. 18 (1988) 568.

[22] M. Endo, Y.A. Kim, T. Hayashi, K. Nishimura, T. Matusita, K. Miyashita, M.S. Dresselhaus, Carbon 39 (2001) 1287.

[23] M. Nakagawa, T. Wada, S. Kamado, Y. Kojima, J. Japan Inst. Metals 45 (1995) 21.

[24] I. Schroder, K.U. Kainer, B.L. Mordike, Developments in the Science and Technology of Composite Materials, ECCM 3, Bordeatt IX, France, 20-23 March 1989.

[25] M. Russell-Stevens, R. Todd, M. Papakyriacou, Surf. Interface Anal. 7 (2005) 336.

[26] A. Bag, W. Zhou, J. Mater. Sci. Lett. 20 (2001) 457. 


\section{Caption of figures}

Figure 1 SEM images: $(a, b)$ of mechanically milled AZ91D-type magnesium powders with an average diameter of $100 \mu \mathrm{m}$ and shortened carbon nanotubes with an average length of $\sim 5$ $\mu \mathrm{m}$; (c, d) mechanically mixed magnesium powders containing $1 \%$ and $5 \%$ short carbon nanotubes, respectively. Note that the aggregated carbon nanotubes were observed in magnesium powders containing $5 \%$ of carbon nanotubes (inset is a magnified SEM image). (f) Photo of carbon nanotube-reinforced magnesium composite-based rod exhibiting clean appearance without any macro-morphological defects (inset is a photo of clean shining two volts fabricated from extruded rods).

Figure 2 Stress-strain curves for the pristine and carbon nanotube-filled AZ91D magnesium alloy composites, respectively.

Figure 3 (a-c) EPMA for the cross section of AZ91D/CNT1\%-based specimen, (d) SEM image of chemically etched surface exhibiting highly dispersed singular nanotubes. Circles indicate an isolated singular carbon nanotube.

Figure 4 (a) TEM image of 1\% nanotube-reinforced AZ91D-type magnesium alloy composite; (b) elemental Mg mapping (in yellow) of the TEM image in (a); (c) elemental Al mapping (in light yellow) of the TEM image in (a); (d) elemental C mapping (in light red) of the TEM image in (a). TEM images showing the characteristic facetted cross sectional nanotube (e) and linear lattices (f) contacted with magnesium alloy, revealing that there was the absence of void and new phase between nanotube and magnesium alloy. (For interpretation of the references to color in this figure legend, the reader is referred to the web version of this article.)

Figure 5 Optical photographs of (a) pristine, 1\% (b) and $5 \%$ (c) reinforced magnesium alloys. Note that there is no large difference in grain sizes. 

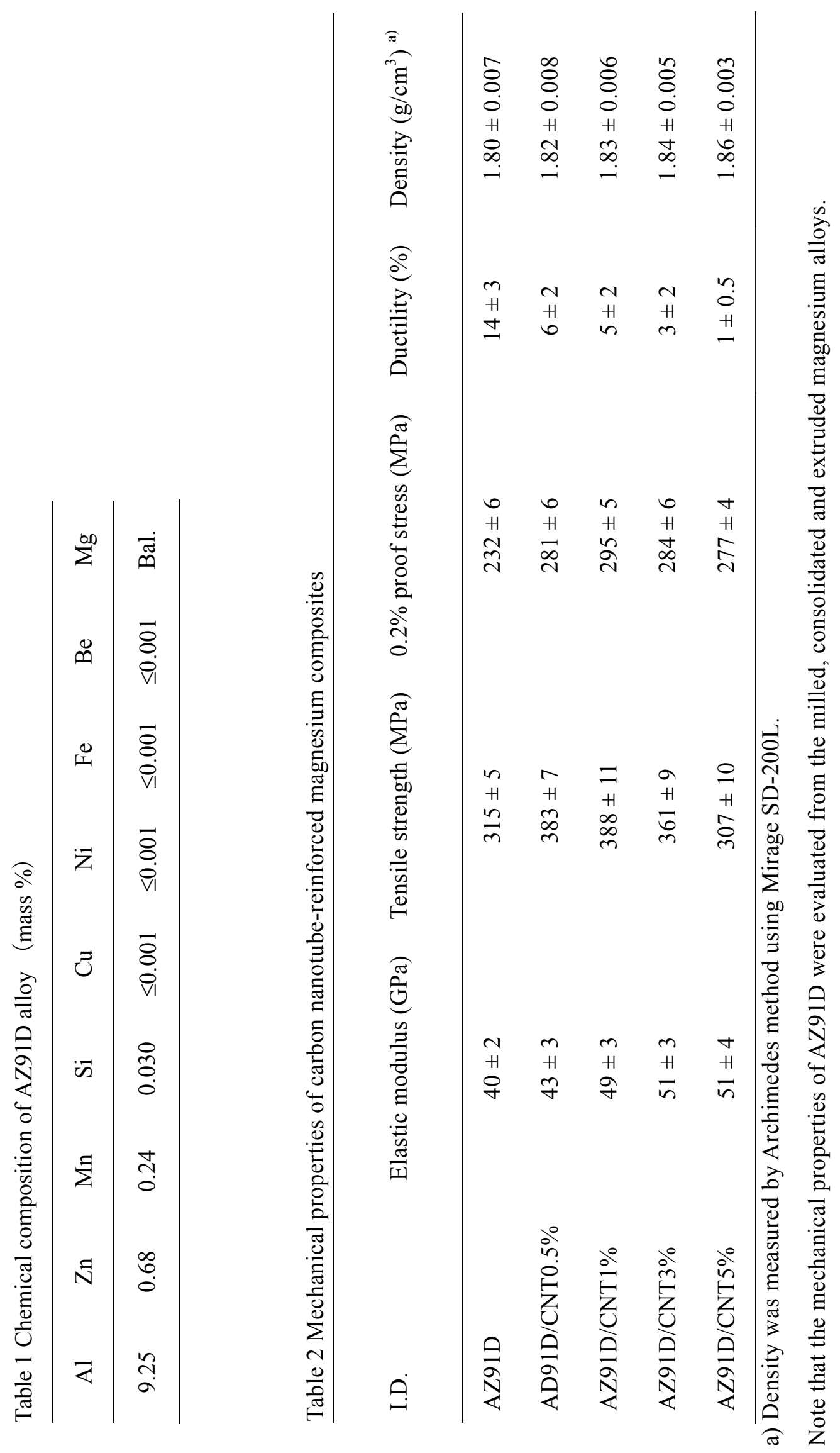


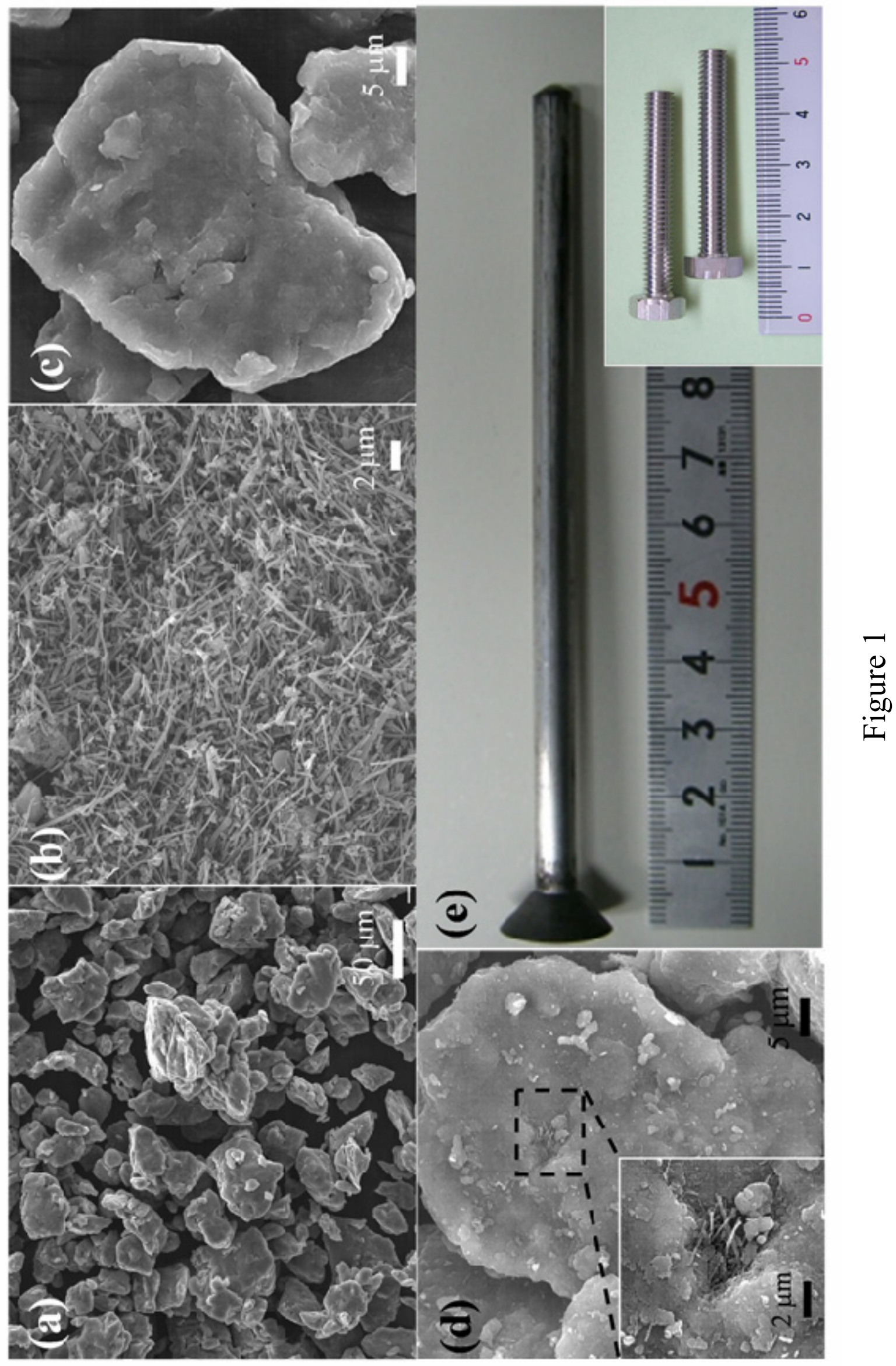




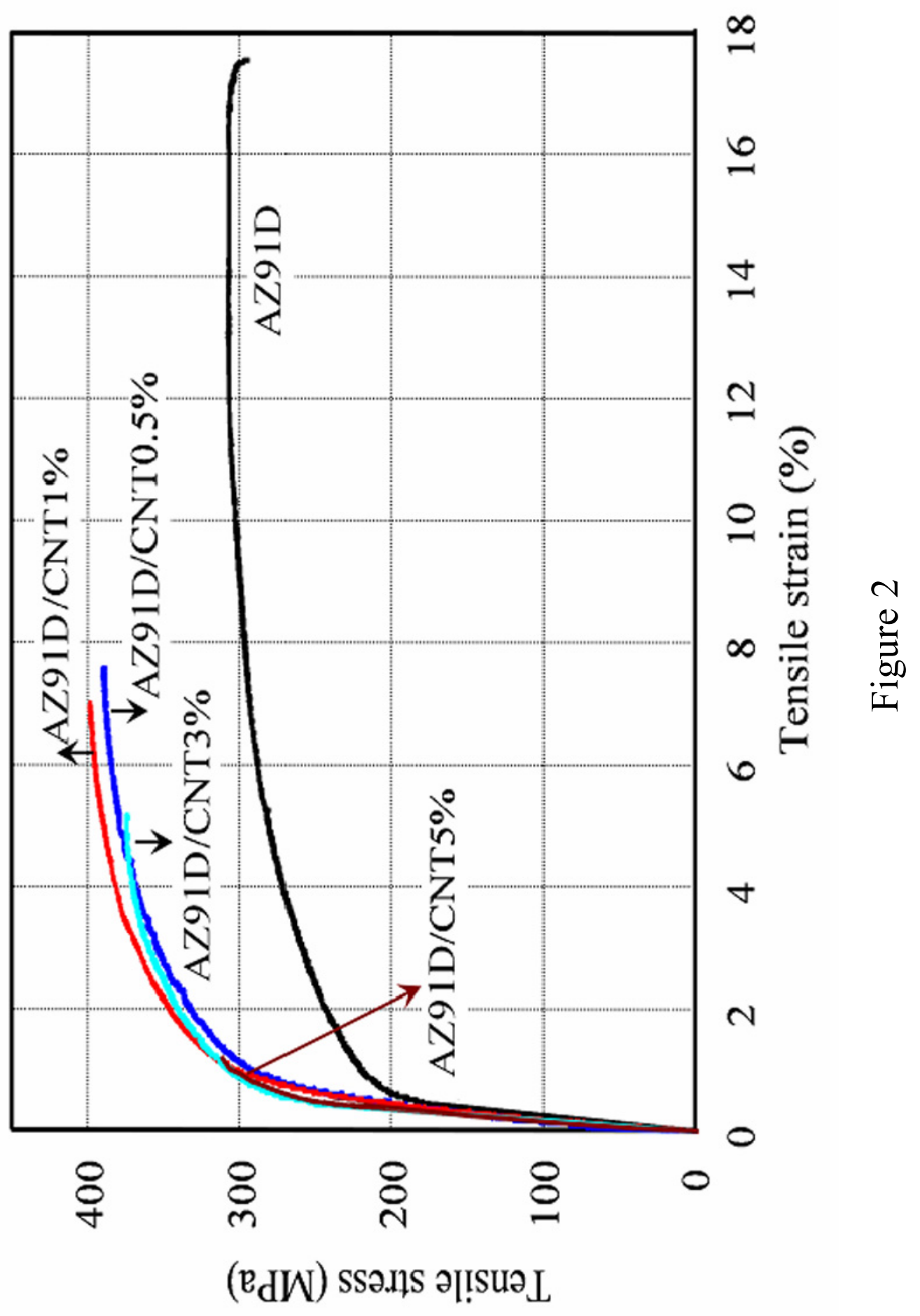



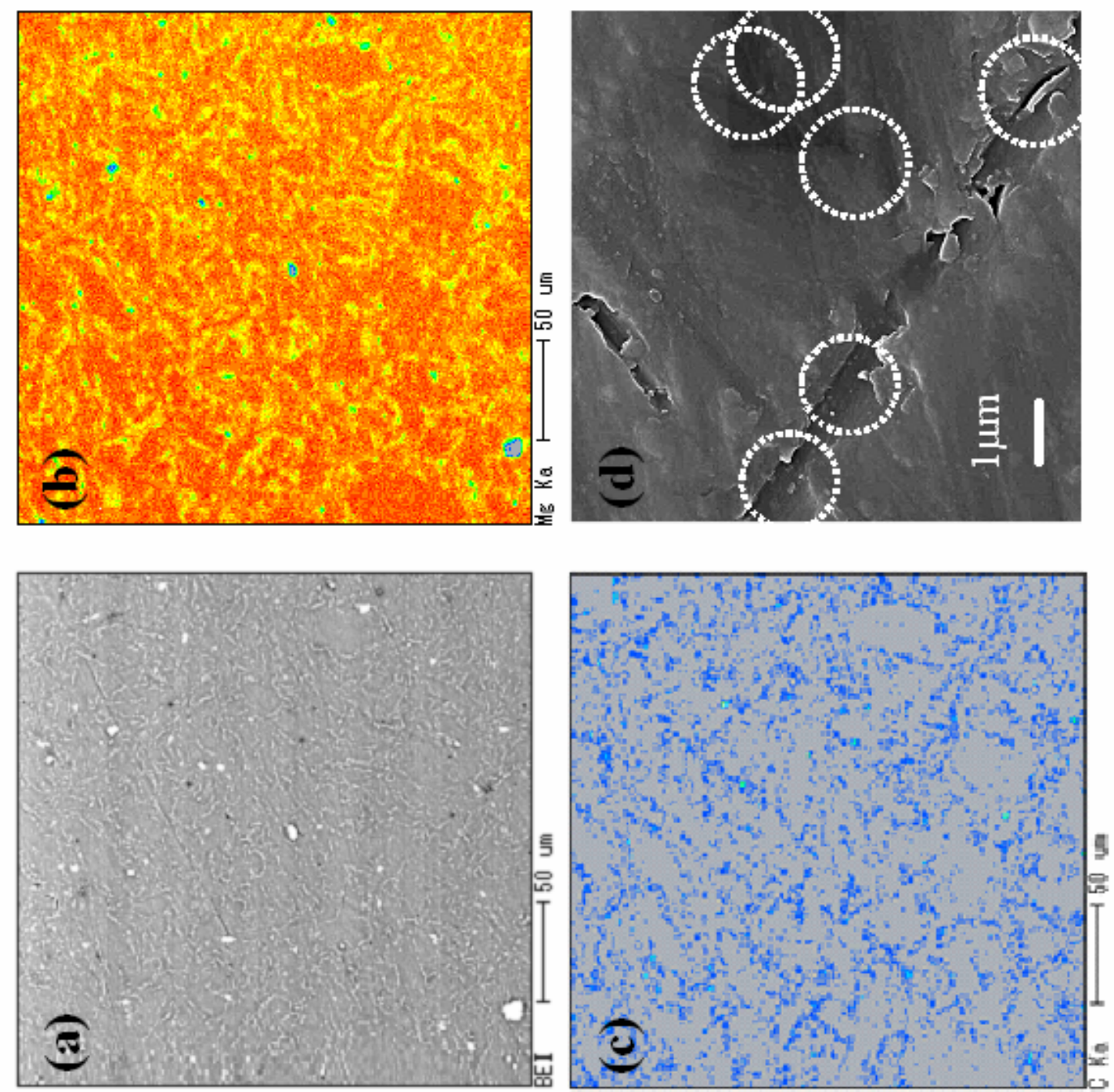

常 


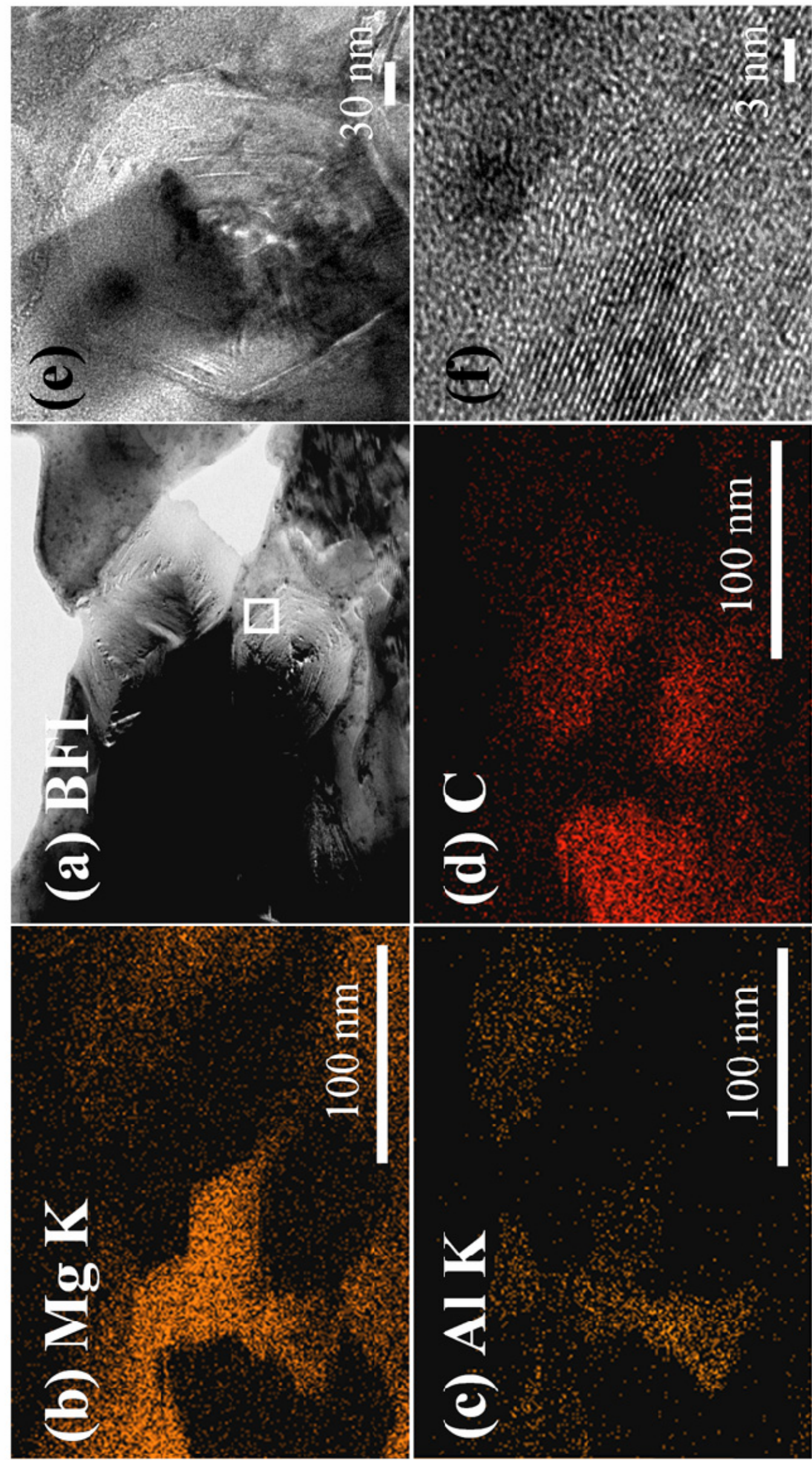

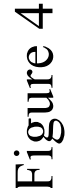




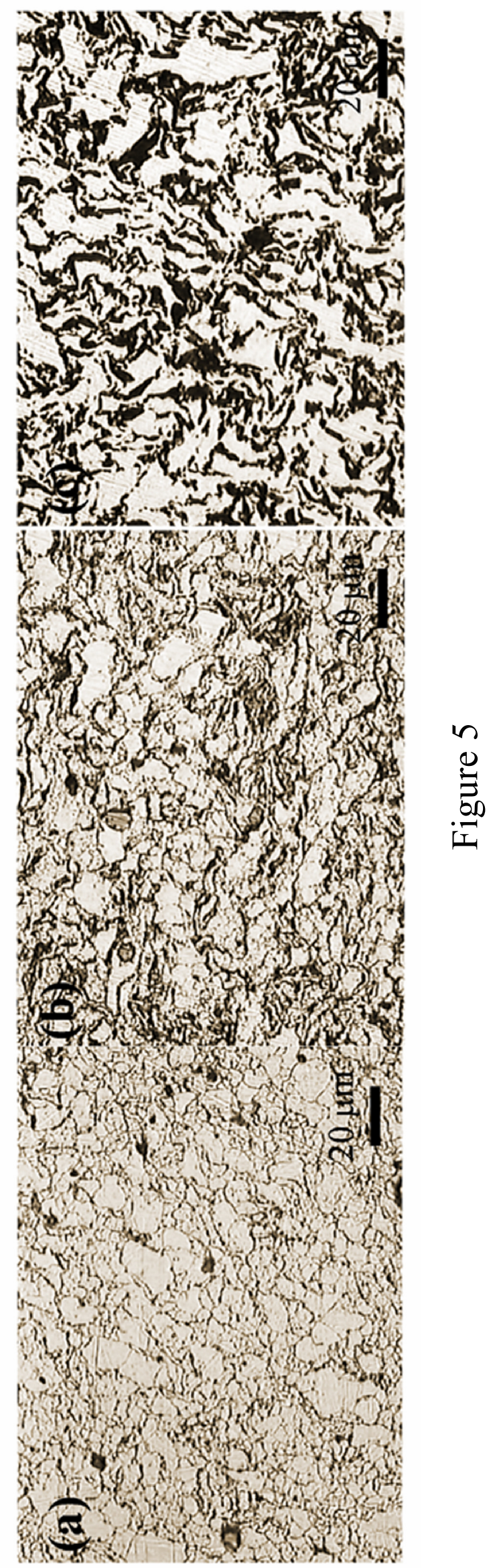

